Chapman University

Chapman University Digital Commons

Pharmacy Faculty Articles and Research

School of Pharmacy

2006

\title{
Methods for the Study of Signaling Molecules in Membrane Lipid Rafts and Caveolae
}

Rennolds S. Ostrom

Chapman University, rostrom@chapman.edu

Paul A. Insel

University of California, San Diego

Follow this and additional works at: http://digitalcommons.chapman.edu/pharmacy_articles

Part of the Amino Acids, Peptides, and Proteins Commons, Cell Biology Commons, and the Other Pharmacy and Pharmaceutical Sciences Commons

\section{Recommended Citation}

Rennolds S. Ostrom and Paul A. Insel. Methods for the study of signaling molecules in membrane lipid rafts and caveolae. Methods Mol Biol, 332:181-91, 2006.

This Article is brought to you for free and open access by the School of Pharmacy at Chapman University Digital Commons. It has been accepted for inclusion in Pharmacy Faculty Articles and Research by an authorized administrator of Chapman University Digital Commons. For more information, please contact laughtin@chapman.edu. 


\section{Methods for the Study of Signaling Molecules in Membrane Lipid Rafts and Caveolae}

\section{Comments}

This is a pre-copy-editing, author-produced PDF of an article accepted for publication in Methods in Molecular Biology, volume 332, in 2006 following peer review. The final publication is available at Springer via DOI:

10.1385/1-59745-048-0:181

\section{Copyright}

Springer 


\title{
Methods for the study of signaling molecules in membrane lipid rafts and caveolae
}

\author{
Rennolds S Ostrom, Ph.D. ${ }^{1}$ and Paul A. Insel, M.D. ${ }^{2}$ \\ ${ }^{1}$ Department of Pharmacology and the Vascular Biology Center of Excellence \\ University of Tennessee Health Science Center \\ Memphis, TN 38163 \\ ${ }^{2}$ Departments of Pharmacology and Medicine \\ School of Medicine \\ University of California, San Diego \\ La Jolla, CA 92093
}

Corresponding author: Paul A. Insel

Department of Pharmacology, 0636

University of California, San Diego

La Jolla, CA 92093-0636

(858) 534-2295 (858) 822-1007 (FAX)

pinsel@ucsd.edu

Work in the authors' laboratories related to this topic is supported by grants from the National Institutes of Health. 


\begin{abstract}
Lipid rafts and caveolae are cholesterol- and sphingolipid-rich microdomains of the plasma membrane that concentrate components of certain signal transduction pathways. Interest in and exploration of these microdomains has grown in recent years, especially following the discovery of the biochemical marker of caveolae, caveolin, and the recognition that caveolin interacts with many different signaling molecules via its scaffolding domain. There are 3 major types of caveolins (1,2, and 3) with some selectivity in their expression in different tissues. Results assessing lipid raft/caveolae co-localization of molecules in signal transduction pathways provided support for the idea that signaling components are compartmentalized or pre-assembled together. This chapter describes non-detergent and detergent-based methods for isolating lipid rafts and caveolae for biochemical studies. We also describe a method for immunoisolation (using antibodies to caveolins) of detergent-insoluble membranes that selectively isolates caveolae versus lipid rafts. Together, these methods are useful for assessment of the role of lipid rafts and caveolae in transmembrane signaling.
\end{abstract}

Key words: lipid rafts, caveolae, membrane microdomains, plasma membrane vesicles, density gradient centrifugation, immunoprecipitation, immunoisolation. 


\section{Introduction}

Recent investigations have identified caveolae and lipid rafts as important microdomains of the plasma membrane that concentrate and perhaps "pre-assemble" the components of signal transduction pathways $[1,2]$. The enrichment of a large array of signal transduction components in those domains [3] suggests that caveolae and lipid rafts are signaling centers, whose role in physiologic and pathophysiologic processes is the subject of intense investigation. Caveolae ("little caves") were morphologically identified in the 1950's as flask-like, 50-100 nm invaginations of the plasma membrane of endothelial cells and later shown to be involved in potocytosis, endocytosis and transcellular movement of molecules $[4,5]$. Endocytosis by caveolae differs from that mediated by another specialized region of the plasma membrane, clathrin-coated pits. These two vesicular structures differ biochemically and transport different types of molecules, and thus represent parallel but distinct pathways [5].

Lipid rafts form via the coalescence of particular lipids, most prominently sphingolipids and cholesterol (12). Caveolae have a similar lipid composition to rafts but also contain a "coat" of caveolin proteins on the inner leaflet of the membrane bilayer [6]. While all mammalian cells appear to contain plasma membrane lipid rafts [7], only cells expressing caveolins express caveolae (for example, leukocytes contain lipid rafts but no caveolae). There are 3 isoforms of caveolin, caveolin-1, caveolin-2, and caveolin-3; caveolae can form if cells express either caveolin-1, the predominant isoform, or caveolin-3, the striated muscle-specific isoform [8,9]. Caveolin-2 does not appear to induce caveolae formation, but is found in hetero-oligomers with caveolin-1 and caveolin-3 [10-14]. Although caveolae are generally considered subsets of lipid rafts due to their similar lipid composition, the two entities likely differ in a variety of ways [1517]. By their original definition, caveolae are discrete morphologic structures identifiable at the 
electron microscopic level, however lipid rafts cannot readily be identified by microscopic techniques (except by atomic force microscopy [18]).

Lipid rafts and caveolae are most readily studied with biochemical approaches. Cells are disrupted and the lipid rafts and caveolae are then extracted from other cellular material, generally based upon their relative insolubility and buoyancy in certain detergent or nondetergent conditions. Most commonly, lipid rafts and caveolae are isolated by virtue of their high buoyancy when centrifuged on a density gradient consisting of either a discontinuous gradient of sucrose [5, 19-21], as we describe here, or a continuous gradient of Optiprep, as described elsewhere $[22,23]$. These approaches, which rely upon properties common to both lipid rafts and caveolae, do not distinguish between these domains. Caveolae can be preferentially isolated from lipid rafts, however, using immunological approaches to trap caveolin-rich membrane domains $[24,25]$. We describe one general method for isolating caveolae from cells and tissues in this chapter. Another method developed by Oh and Schnitzer isolates caveolae using immunoisolation of caveolin; this method is particularly suitable for cells or tissues with high levels of expression of caveolins and caveolae, such as pulmonary vascular endothelia [24].

Caveolins can also act as scaffolding proteins, whereby other proteins, including proteins involved in signal transduction, bind; such binding generally is associated with an inhibition in signaling activity [2]. Immunoprecipitation of caveolin proteins or expression of peptides that interfere with the caveolin-binding motif, the domain on caveolin-1 and caveolin-3 that binds those other proteins [2], can be used to assess the role of the putative caveolin scaffold. Caveolin protein overexpression and knockout has also been used to examine the role of these proteins in physiology and signal transduction [26]. Because caveolins act as regulators of several signal 
transduction pathways [6], alteration in their expression by such approaches cannot be considered a pure "probe" of the compartmentation of a particular signaling pathway in caveolae. The function of lipid rafts and caveolae in signaling or other cellular processes can also be inferred from studies in which the microdomains are disrupted. Methyl-ß3-cyclodextrin, a chemical that does not enter cells but can bind cholesterol and remove it from the plasma membrane, disrupts lipid rafts and caveolae [27]. Filipin, a polyene antibiotic and sterol-binding agent, also disrupts lipid rafts and caveolae [28, 29]. This chapter does not describe these methodologies but interested readers may wish to consult articles describing their use $[19,28$, $30]$.

Microscopic studies are useful and sometimes important for corroboration of results from biochemical studies of lipid rafts and caveolae. However, such approaches, not described here, are limited by their inability to detect lipid rafts (as noted above), the poor resolution of light and fluorescent microscopy for the identification of caveolae, and the variable ability and availability of suitable antibodies to detect the proteins of interest. With suitable antibodies, one can assess protein localization using double immunostaining and electron microscopy. Cholera toxin, which binds to GM1 ganglioside enriched in lipid rafts [28], can be used as a marker of lipid rafts and caveolae while caveolin can be used as a marker of caveolae. Atomic force microscopy, which can detect the surface topology of cell membranes, is a technique with future promise for visualizing lipid rafts [18]. Other technologies, such as fluorescence resonance energy transfer (FRET) and bioluminescence energy transfer (BRET), are powerful tools for examination of interaction of components but their use is limited to the examination of exogenously expressed proteins with fluorescent/luminescent tags [31]. 
In this chapter, we describe non-detergent and detergent-based methods for isolating lipid rafts/caveolae and caveolae. We describe some variations of this general approach that can be useful in specific circumstances and we present complementary methods to address the question of signaling in lipid rafts or caveolae. We also describe a method for immunoisolation of detergent-insoluble membranes that selectively isolates caveolae versus lipid rafts. Each method has advantages and disadvantages that should be considered when choosing an experimental approach to answer a particular biological question. Non-detergent fractionation of cells retains certain proteins in lipid raft/caveolar fractions that can be lost upon detergent solubilization [22, 32]. On the other hand, detergent-based approaches can allow the measurement of protein function, such as enzyme activity, while the non-detergent methods (due to high $\mathrm{pH}$ and high energy sonication) do not. We believe that it is generally desirable to use a combination of different, complementary approaches, along with immunoprecipitation (i.e. "pull-down" of proteins in detergent conditions that solubilize all membrane proteins, [not described herein]) to assess protein-protein interactions, in order to study signal transduction in lipid rafts and caveolae.

\section{Materials}

1. PBS: phosphate buffered saline

2. $500 \mathrm{mM} \mathrm{Na}_{2} \mathrm{CO}_{3}$ (should be approximately $\mathrm{pH} 11$, but do not adjust).

3. MBS: $25 \mathrm{mM}$ MES, $150 \mathrm{mM} \mathrm{NaCl}, \mathrm{pH} 6.0$.

4. $\mathrm{MBS} / \mathrm{Na}_{2} \mathrm{CO}_{3}: \mathrm{MBS}, 250 \mathrm{mM} \mathrm{Na} \mathrm{CO}_{3}$.

5. $90 \%$ Sucrose/MBS: dissolve $45 \mathrm{~g}$ sucrose with MBS until volume equals $50 \mathrm{ml}$. Heat in a microwave oven (in $10 \mathrm{sec}$ intervals) to dissolve/melt. 
6. $35 \%$ Sucrose in $\mathrm{MBS} / \mathrm{Na}_{2} \mathrm{CO}_{3}: 5.83 \mathrm{~mL} 90 \%$ Sucrose/MBS plus $9.17 \mathrm{~mL} \mathrm{MBS} / \mathrm{Na}_{2} \mathrm{CO}_{3}$.

7. $5 \%$ Sucrose in $\mathrm{MBS} / \mathrm{Na}_{2} \mathrm{CO}_{3}: 0.83 \mathrm{~mL} 90 \%$ Sucrose/MBS plus $14.17 \mathrm{~mL}$ $\mathrm{MBS} / \mathrm{Na}_{2} \mathrm{CO}_{3}$.

8. Triton X-100 Buffer: MBS, $1 \%$ Triton X-100, protease inhibitor mix (Sigma P-8340, diluted 1:100).

9. 35\% Sucrose in MBS/Triton X-100: $5.83 \mathrm{~mL}$ 90\% Sucrose/MBS plus $9.17 \mathrm{~mL}$ Triton X100 buffer.

10. $5 \%$ Sucrose in $\mathrm{MBS} / \mathrm{Na}_{2} \mathrm{CO}_{3}: 0.83 \mathrm{~mL} 90 \%$ Sucrose/MBS plus $14.17 \mathrm{~mL}$ Triton $\mathrm{X}-100$ buffer.

11. Membrane Buffer: $0.25 \mathrm{M}$ sucrose, $1 \mathrm{mM}$ EDTA, $20 \mathrm{mM}$ Tricine, $\mathrm{pH} 7.8$

12. $30 \%$ Percoll: $3 \mathrm{~mL}$ Percoll stock solution diluted in $9 \mathrm{~mL}$ PBS.

13. Modified Lysis Buffer: $50 \mathrm{mM}$ Tris-HCl, pH 7.5, $150 \mathrm{mM} \mathrm{NaCl}, 1 \mathrm{mM}$ EGTA, $10 \mathrm{mM}$ $\mathrm{MgCl}_{2}, 0.5 \%$ Triton X-100, protease inhibitor mix (Sigma P-8340, diluted 1:100).

14. Protein A-agarose and protein G-agarose

15. Immunoprecipitation (IP) Wash Buffer 1: $50 \mathrm{mM}$ Tris-HCl, $\mathrm{pH} 7.5,500 \mathrm{mM} \mathrm{NaCl}$, $0.2 \%$ Triton X-100.

16. IP Wash Buffer 2: 10 mM Tris-HCl, pH 7.5, 0.2\% Triton X-100.

\section{Methods}

\subsection{Isolation of lipid rafts and caveolae by sucrose density centrifugation}

This method relies upon the unique lipid composition (with enrichment in sphingolipid and cholesterol) of lipid rafts and caveolae, which makes these membrane domains resistant to solubilization in certain conditions as well as more buoyant than other cellular lipids. We describe the method for adherent cells in tissue culture but it can be readily adapted for cells in 
suspension or for tissue samples. We have found that two $150 \mathrm{~mm}$ plates of cells is adequate for one preparation.

\subsubsection{Sodium carbonate isolation of lipid rafts and caveolae.}

1. Check that cells are at least $70 \%$ confluent. One preferably grows cells on $150 \mathrm{~mm}$ tissue culture plates (dishes) to optimize the amount of starting material. Aspirate medium and wash 3 times with ice-cold PBS. On the last wash, be sure to remove all PBS by tilting the plate at a steep angle for $30 \mathrm{sec}$ then aspirating all liquid.

2. Apply $1 \mathrm{~mL}$ of $500 \mathrm{mM} \mathrm{Na}_{2} \mathrm{CO}_{3}$ to each $150 \mathrm{~mm}$ plate and make sure it covers the entire monolayer. Scrape cells from the plate with a cell scraper, making sure to retain as much cellular material as possible.

3. Transfer the cells from two plates ( $2 \mathrm{~mL}$ total) to a pre-chilled Dounce (glass-glass) homogenizer and homogenize the cells with 20 strokes on ice.

4. Transfer the homogenate to a cold $50 \mathrm{ml}$ Falcon tube and homogenize with a polytron 3 times for 10 seconds with intervals of $10-15 \mathrm{sec}$. Rinse the polytron blade with $0.5 \mathrm{ml}$ of $500 \mathrm{mM} \mathrm{Na} \mathrm{CO}_{3}$ into the sample to recover all possible material.

5. Homogenize the sample using an ultrasonic cell disruptor equipped with a stainless steel probe at high power 3 times for $20 \mathrm{sec}$ each with a full $60 \mathrm{sec}$ rest between each homogenization.

6. Proceed to section 3.1.4.

\subsubsection{Detergent isolation of lipid rafts and caveolae}

1. Check that cells are at least $70 \%$ confluent. Aspirate medium and wash 3 times with icecold PBS. On the last wash, be sure to remove all PBS by tilting the plate at a steep angle for $30 \mathrm{sec}$ and then aspirating all liquid. 
2. Apply $1 \mathrm{~mL}$ of $1 \%$ Triton-X 100 buffer to each $150 \mathrm{~mm}$ plate so that it covers the entire monolayer (see Note 1). Scrape cells from the plate with a cell scraper making sure to retain as much cellular material as possible.

3. Transfer the cells from two plates ( $2 \mathrm{~mL}$ total) to a pre-chilled Dounce (glass-glass) homogenizer and incubate on ice for $20 \mathrm{~min}$. Homogenize the cells with 20 strokes on ice.

4. Proceed to section 3.1.4.

\subsubsection{Variation: Isolation of lipid rafts and caveolae from plasma membranes}

1. Check that cells are at least $70 \%$ confluent. Aspirate medium and wash 3 times with icecold PBS. On the last wash, be sure to remove all PBS by tilting the plate at a steep angle for $30 \mathrm{sec}$ and then aspirating all liquid.

2. Apply $1 \mathrm{~mL}$ of Membrane buffer to each $150 \mathrm{~mm}$ plate so that it covers the entire monolayer. Scrape cells from the plate with a cell scraper making sure to retain as much cellular material as possible.

3. Collect the cells from two plates $(2 \mathrm{~mL}$ total) and homogenize cells with 20 strokes in a Dounce (glass-glass) or Teflon-glass homogenizer on ice then centrifuge at $300 \mathrm{~g}$ for 5 min and collect the supernatant.

4. Layer the supernatant on top of $30 \%$ Percoll and centrifuge at $64,000 g(19,000 \mathrm{rpm}$ on a SW41 rotor for a Beckman ultracentrifuge) for $30 \mathrm{~min}$.

5. Collect the opaque band near the top of the Percoll layer as plasma membrane (PM).

6. Adjust $\mathrm{PM}$ to $500 \mathrm{mM} \mathrm{Na} \mathrm{CO}_{3}$ by adding an equal volume of $1 \mathrm{M} \mathrm{Na}_{2} \mathrm{CO}_{3}$ and sonicate 3 times for $20 \mathrm{sec}$ with full $60 \mathrm{sec}$ rests between intervals.

\subsubsection{Sucrose density centrifugation to fractionate cell homogenates}


Once cells or tissues are homogenized using one of the above approaches (3.1.1, 3.1.2 or 3.1.3), the lipid raft/caveolar fraction can be isolated using sucrose density centrifugation. As explained above, this method relies upon the unique lipid composition of the lipid raft/caveolae (rich is sphingolipid and cholesterol), which makes these domains of the membrane more buoyant than other cellular components. A schematic diagram of this fractionation, as shown in Figure 1 and as described subsequently, involves use of a discontinuous gradient, although a continuous gradient can also be employed.

1. Mix $2.0 \mathrm{~mL}$ of homogenized sample (leaving any foam behind) with $2.0 \mathrm{~mL}$ of $90 \%$ sucrose/MBS in an ultracentrifuge tube. Save any remaining sample as whole cell lysate.

2. Carefully layer $4 \mathrm{~mL}$ of either $35 \%$ Sucrose in $\mathrm{MBS} / \mathrm{Na}_{2} \mathrm{CO}_{3}$ (if sample was homogenized by non-detergent method, Sections 3.1 .1 or 3.1.3) or 35\% Sucrose in MBS/Triton X-100 Buffer (if sample was homogenized by detergent method, Section 3.1.2) on top of the sample/90\% sucrose/MBS layer. A visible interface should exist between the two density layers.

3. Carefully layer $4 \mathrm{~mL}$ of either $5 \%$ Sucrose in $\mathrm{MBS} / \mathrm{Na}_{2} \mathrm{CO}_{3}$ (if sample was homogenized by non-detergent method, Sections 3.1.1 or 3.1.3) or 5\% Sucrose in MBS/Triton X-100 Buffer (if sample was homogenized by detergent method, Section 3.1.2) on top of the $35 \%$ sucrose layer. A second interface should be visible between the $35 \%$ sucrose and the $5 \%$ sucrose layers and the ultracentrifuge tube should be nearly full.

4. Centrifuge for $16-20$ hours at $39,000 \mathrm{rpm}\left(4^{\circ} \mathrm{C}\right)$ in SW41Ti rotor (Beckman), equivalent to a maximum force (bottom of tube) of approximately $260,000 \mathrm{x} g$ and an average force (middle of the tube) of approximately $188,000 \mathrm{xg}$ (see Note 2). 
5. At the completion of the centrifugation, carefully remove the ultracentrifuge tube from the bucket. A faint light-scattering band, which consists of the buoyant lipid raft/caveolar material, is often visible at the $35 \%$ sucrose- $5 \%$ sucrose interface.

6. Collect samples from the gradient from the top down as $1 \mathrm{ml}$ fractions, being careful to keep the pipet at the top of the liquid in order to draw each fraction appropriately.

7. Fractions can then be analyzed by SDS-PAGE and immunoblotting (see Note 3).

\subsection{Immunoisolation of caveolae}

With this method, one takes advantage of the reduced solubility of lipid rafts and caveolae to detergent in order to isolate these domains from the rest of the cellular material (as in section 3.1.2) and one then selectively "traps" caveolae (vs. lipid rafts) by using an antibody to immunoprecipitate caveolin (and associated lipids and proteins). Antibodies to any of the caveolin isoforms can be used, but these should be chosen carefully based upon expression of caveolins in the cell or tissue of interest. With this method one has the potential to maintain enzyme and receptor binding activity, thus allowing one to assess protein function. We have used this approach to assay receptor-activated adenylyl cyclase activity in caveolae from cardiac myocytes [25] and other cells, thus the function of other proteins are likely also maintained.

1. Check that cells are at least $70 \%$ confluent. Aspirate medium and wash 3 times with icecold PBS. On the last wash, be sure to remove all PBS by tilting plate at a steep angle for $30 \mathrm{sec}$ and then aspirating all liquid.

2. Add $2 \mathrm{ml}$ of Modified Lysis Buffer to each $15 \mathrm{~cm}$ plate. Homogenize cells with 20 strokes in a Dounce (glass-glass) homogenizer. 
3. Transfer to a $1.5 \mathrm{ml}$ microtube and add $50 \mu \mathrm{l}$ of either protein $\mathrm{G}$ - or Protein A-agarose suspension (see Note 4). Incubate at $4^{\circ} \mathrm{C}$ on a rocking platform for $1 \mathrm{hr}$.

4. Centrifuge in a micro centrifuge at max speed (12,000 to $14,000 \mathrm{rpm})$ for $30 \mathrm{sec}$ to pellet agarose and then transfer the supernatant to a new tube.

5. Add primary antibody (1-3 $\mu 1$, depending on the antibody concentration) and gently mix (preferably by rocking) at $4^{\circ} \mathrm{C}$ for $1 \mathrm{hr}$.

6. Add $50 \mu 1$ protein $\mathrm{A}$ - or protein $\mathrm{G}$-agarose to tube and incubate at $4^{\circ} \mathrm{C}$ on a rocking platform for $1 \mathrm{hr}$.

7. Centrifuge in a micro centrifuge at max speed $(12,000$ to $14,000 \mathrm{rpm})$ for $30 \mathrm{sec}$ to pellet agarose. Supernatant should be saved as the IP supernatant and used as a control.

8. Add $1 \mathrm{ml}$ of Modified Lysis Buffer to pellet, mix and rock at $4^{\circ} \mathrm{C}$ for $5 \mathrm{~min}$.

9. Centrifuge in a micro centrifuge at max speed (12,000 to $14,000 \mathrm{rpm})$ for $30 \mathrm{sec}$ to pellet agarose, remove supernatant and add $1 \mathrm{ml}$ of Wash Buffer 1 to pellet, mix and rock at $4^{\circ} \mathrm{C}$ for $5 \mathrm{~min}$.

10. Centrifuge in a micro centrifuge at max speed $(12,000$ to $14,000 \mathrm{rpm})$ for $30 \mathrm{sec}$ to pellet agarose, remove supernatant and add $1 \mathrm{ml}$ of Wash Buffer 2 to pellet, mix and rock at $4^{\circ} \mathrm{C}$ for $5 \mathrm{~min}$.

11. The final pellet should then be suspended in a suitable assay buffer (if enzyme activity is to be measured) and/or in sample buffer for analysis by SDS polyacrylamide gel electrophoresis (for immunoblotting). Immunoblot analysis should be performed on a portion of the immunoprecipitated pellet and supernatants to confirm appropriate immunoprecipitation and to assess which proteins have been co-precipitated with the target protein. 


\section{Notes}

1. Non-ionic detergents other than Triton X-100, including NP-40, octylglucoside, CHAPS, Lubrol, and Brij 98, can be used to solubilize cells and isolate lipid raft and caveolar domains [19]. In addition, some investigators have used concentrations of Triton X-100 lower than $1 \%$ in protocols similar to that described above.

2. Other rotors can be used for the sucrose density centrifugation, including a Beckman SW55Ti rotor with $5 \mathrm{ml}$ buckets. In this case $1 \mathrm{ml}$ of cell homogenate is mixed with $1 \mathrm{ml}$ $90 \%$ sucrose and $2 \mathrm{ml}$ of $35 \%$ sucrose and $1 \mathrm{ml} 5 \%$ sucrose is layered on top. The rotation speed is adjusted to maintain equivalent $\mathrm{g}$ forces. Fractions are collected in 0.5 $\mathrm{ml}$ aliquots to yield 10 fractions.

3. It is critical to determine the appropriateness of each fractionation by performing immunoblot analysis for markers of cellular organelles. Fractions from the 5\% sucrose/35\% sucrose interface (numbers 4 and 5) should contain the bulk of any caveolin immunoreactivity but exclude markers of clathrin-coated pits (such as adaptin- $\beta$ ), Golgi apparatus (such as mannosidase II) and other cellular organelles for the markers discussed above. The total protein in each fraction can also be used as an indicator of appropriate fractionation. The buoyant fractions from most cells contain approximately $5 \%$ or less of the total cellular protein. Individual fractions from the gradient can be pooled into a buoyant fraction (collected from the 5\%-35\% sucrose interface) and a nonbuoyant fraction (consisting of the entire $45 \%$ sucrose layer), if desired, in order to facilitate rapid screening of antibodies. This approach simplifies immunoblot analysis when the localization of many different proteins needs to be assessed. However, it is wise to collect individual fractions as described above and then to combine a portion of 
these fractions to form pooled fractions, saving some portion of the individual fractions at $-70^{\circ} \mathrm{C}$ for future use. See Figure 1. When immunoblot analysis of fractions is planned, it is best to add SDS-PAGE sample buffer to each fraction and to denature at $-70^{\circ} \mathrm{C}$ for 10 min immediately after collecting the gradient. This will ensure more reproducible results when storing frozen samples for extended periods. For detection of low abundance proteins, samples can also be concentrated in Speed-vac (or similar type) concentrator before addition of sample buffer. However, the fractions from the bottom of the gradient will not concentrate as well because of the presence of higher concentrations of sucrose. Dialysis can also be used to remove sucrose and to concentrate the samples.

4. When performing any type of immunoprecipitation, one should carefully choose between protein A-agarose and protein G-agarose for precipitation of the primary antibody. Protein A has high affinity for human, rabbit, guinea pig and pig IgG's and moderate affinity for mouse, horse and cow IgG's. Protein G has high affinity for human, horse, cow, pig and rabbit IgG's and moderate affinity for sheep, goat, chicken, hamster, guinea pig, rat and mouse IgG's. Protein A and protein $\mathrm{G}$ also differ in their affinities for different subclasses of IgG's. More information on the different affinities of protein A and protein $\mathrm{G}$ can be found in the product information sheet from Roche Applied Science. 


\section{References}

1. Ostrom, R.S. and P.A. Insel, The evolving role of lipid rafts and caveolae in Groteincoupled receptor signaling: Implications for molecular pharmacology. Br J Pharmacol, 2004. 143(2): p. 235-45.

2. Okamoto, T., A. Schlegel, P.E. Scherer, and M.P. Lisanti, Caveolins, a family of scaffolding proteins for organizing "preassembled signaling complexes" at the plasma membrane. Journal of Biological Chemistry, 1998. 273(10): p. 5419-22.

3. Shaul, P.W. and R.G. Anderson, Role of plasmalemmal caveolae in signal transduction. Am J Physiol, 1998. 275(5 Pt 1): p. L843-51.

4. Palade, G., Fine structure of blood capilaries. Journal of Applied Physiology, 1953. 24: p. 1424.

5. Anderson, R.G., The caveolae membrane system. Annu Rev Biochem, 1998. 67: p. 199225 .

6. Razani, B., S.E. Woodman, and M.P. Lisanti, Caveolae: from cell biology to animal physiology. Pharmacol Rev, 2002. 54(3): p. 431-67.

7. Hooper, N.M., Detergent-insoluble glycosphingolipid/cholesterol-rich membrane domains, lipid rafts and caveolae (review). Molecular Membrane Biology, 1999. 16(2): p. 145-56.

8. Song, K.S., P.E. Scherer, Z. Tang, et al., Expression of caveolin-3 in skeletal, cardiac, and smooth muscle cells. Caveolin-3 is a component of the sarcolemma and cofractionates with dystrophin and dystrophin-associated glycoproteins. Journal of Biological Chemistry, 1996. 271(25): p. 15160-5.

9. Tang, Z., P.E. Scherer, T. Okamoto, et al., Molecular cloning of caveolin-3, a novel member of the caveolin gene family expressed predominantly in muscle. Journal of Biological Chemistry, 1996. 271(4): p. 2255-61.

10. Scherer, P.E., T. Okamoto, M. Chun, et al., Identification, sequence, and expression of caveolin-2 defines a caveolin gene family. Proceedings of the National Academy of Sciences of the United States of America, 1996. 93(1): p. 131-5.

11. Scherer, P.E., R.Y. Lewis, D. Volonté, et al., Cell-type and tissue-specific expression of caveolin-2. Caveolins 1 and 2 co-localize and form a stable hetero-oligomeric complex in vivo. Journal of Biological Chemistry, 1997. 272(46): p. 29337-46. 
12. Razani, B., X.B. Wang, J.A. Engelman, et al., Caveolin-2-deficient mice show evidence of severe pulmonary dysfunction without disruption of caveolae. Mol Cell Biol, 2002. 22(7): p. 2329-44.

13. Rybin, V.O., P.W. Grabham, H. Elouardighi, and S.F. Steinberg, Caveolae-associated proteins in cardiomyocytes: caveolin-2 expression and interactions with caveolin-3. Am J Physiol Heart Circ Physiol, 2003. 285(1): p. H325-32.

14. Lahtinen, U., M. Honsho, R.G. Parton, K. Simons, and P. Verkade, Involvement of caveolin-2 in caveolar biogenesis in MDCK cells. FEBS Lett, 2003. 538(1-3): p. 85-8.

15. Sowa, G., M. Pypaert, and W.C. Sessa, Distinction between signaling mechanisms in lipid rafts vs. caveolae. Proc Natl Acad Sci U S A, 2001. 98(24): p. 14072-7.

16. Williams, T.M. and M.P. Lisanti, The caveolin proteins. Genome Biol, 2004. 5(3): p. 214.

17. Oh, P. and J.E. Schnitzer, Segregation of Heterotrimeric G Proteins in Cell Surface Microdomains. $G(q)$ binds caveolin to concentrate in caveolae, whereas $g(i)$ and $g(s)$ target lipid rafts by default. Mol Biol Cell, 2001. 12(3): p. 685-98.

18. Henderson, R.M., J.M. Edwardson, N.A. Geisse, and D.E. Saslowsky, Lipid rafts: feeling is believing. News Physiol Sci, 2004. 19: p. 39-43.

19. Pike, L.J., Lipid rafts: bringing order to chaos. J Lipid Res, 2003. 44(4): p. 655-67.

20. Ostrom, R.S., S.R. Post, and P.A. Insel, Stoichiometry and Compartmentation in G Protein-coupled Receptor Signaling: Implications for Therapeutic Interventions Involving Gs. Journal of Pharmacology and Experimental Therapeutics, 2000. 294(2): p. 407-12.

21. Song, S.K., S. Li, T. Okamoto, et al., Co-purification and direct interaction of Ras with caveolin, an integral membrane protein of caveolae microdomains. Detergent-free purification of caveolae microdomains. Journal of Biological Chemistry, 1996. 271(16): p. $9690-7$.

22. Smart, E.J., Y.S. Ying, C. Mineo, and R.G. Anderson, A detergent-free method for purifying caveolae membrane from tissue culture cells. Proc Natl Acad Sci U S A, 1995. 92(22): p. 10104-8.

23. Rybin, V.O., X. Xu, M.P. Lisanti, and S.F. Steinberg, Differential targeting of beta adrenergic receptor subtypes and adenylyl cyclase to cardiomyocyte caveolae. A 
mechanism to functionally regulate the cAMP signaling pathway. $\mathrm{J}$ Biol Chem, 2000. 275(52): p. 41447-57.

24. Oh, P. and J.E. Schnitzer, Immunoisolation of caveolae with high affinity antibody binding to the oligomeric caveolin cage. Toward understanding the basis of purification. Journal of Biological Chemistry, 1999. 274(33): p. 23144-54.

25. Ostrom, R.S., C. Gregorian, R.M. Drenan, et al., Receptor number and caveolar colocalization determine receptor coupling efficiency to adenylyl cyclase. J Biol Chem, 2001. 276(45): p. 42063-9.

26. Razani, B. and M.P. Lisanti, Caveolin-deficient mice: insights into caveolar function in human disease. J Clin Invest, 2001. 108(11): p. 1553-61.

27. Smart, E.J. and R.G. Anderson, Alterations in membrane cholesterol that affect structure and function of caveolae. Methods Enzymol, 2002. 353: p. 131-9.

28. Orlandi, P.A. and P.H. Fishman, Filipin-dependent inhibition of cholera toxin: evidence for toxin internalization and activation through caveolae-like domains. J Cell Biol, 1998. 141(4): p. 905-15.

29. Schnitzer, J.E., P. Oh, E. Pinney, and J. Allard, Filipin-sensitive caveolae-mediated transport in endothelium: reduced transcytosis, scavenger endocytosis, and capillary permeability of select macromolecules. J Cell Biol, 1994. 127(5): p. 1217-32.

30. Ostrom, R.S., R.A. Bundey, and P.A. Insel, Nitric oxide inhibition of adenylyl cyclase type 6 activity is dependent upon lipid rafts and caveolin signaling complexes. J Biol Chem, 2004. 279(19): p. 19846-53.

31. Zacharias, D.A., J.D. Violin, A.C. Newton, and R.Y. Tsien, Partitioning of lipid-modified monomeric GFPs into membrane microdomains of live cells. Science, 2002. 296(5569): p. 913-6.

32. Rybin, V.O., X. Xu, and S.F. Steinberg, Activated protein kinase C isoforms target to cardiomyocyte caveolae: stimulation of local protein phosphorylation. Circulation Research, 1999. 84(9): p. 980-8. 


\section{Figure legend:}

Schematic diagram of sucrose density centrifugation method for isolating buoyant fractions consisting of lipid rafts and caveolae. Homogenized cell or tissues lysates in a final concentration of $45 \%$ sucrose are bottom loaded in an ultracentrifuge tube (see Section 3.1). A discontinuous sucrose gradient consisting of $35 \%$ and $5 \%$ sucrose is formed on top of the sample and the gradient is centrifuged for 16-20 hr at approximately $240,000 \mathrm{x} \mathrm{g}$. Buoyant lipid raft and caveolar material will float up to the $35 \%-5 \%$ sucrose interface while the rest of the cellular material will remain in the $45 \%$ sucrose layer. The gradient is typically collected in $1 \mathrm{~mL}$ fractions starting at the top. 
Figure 1:

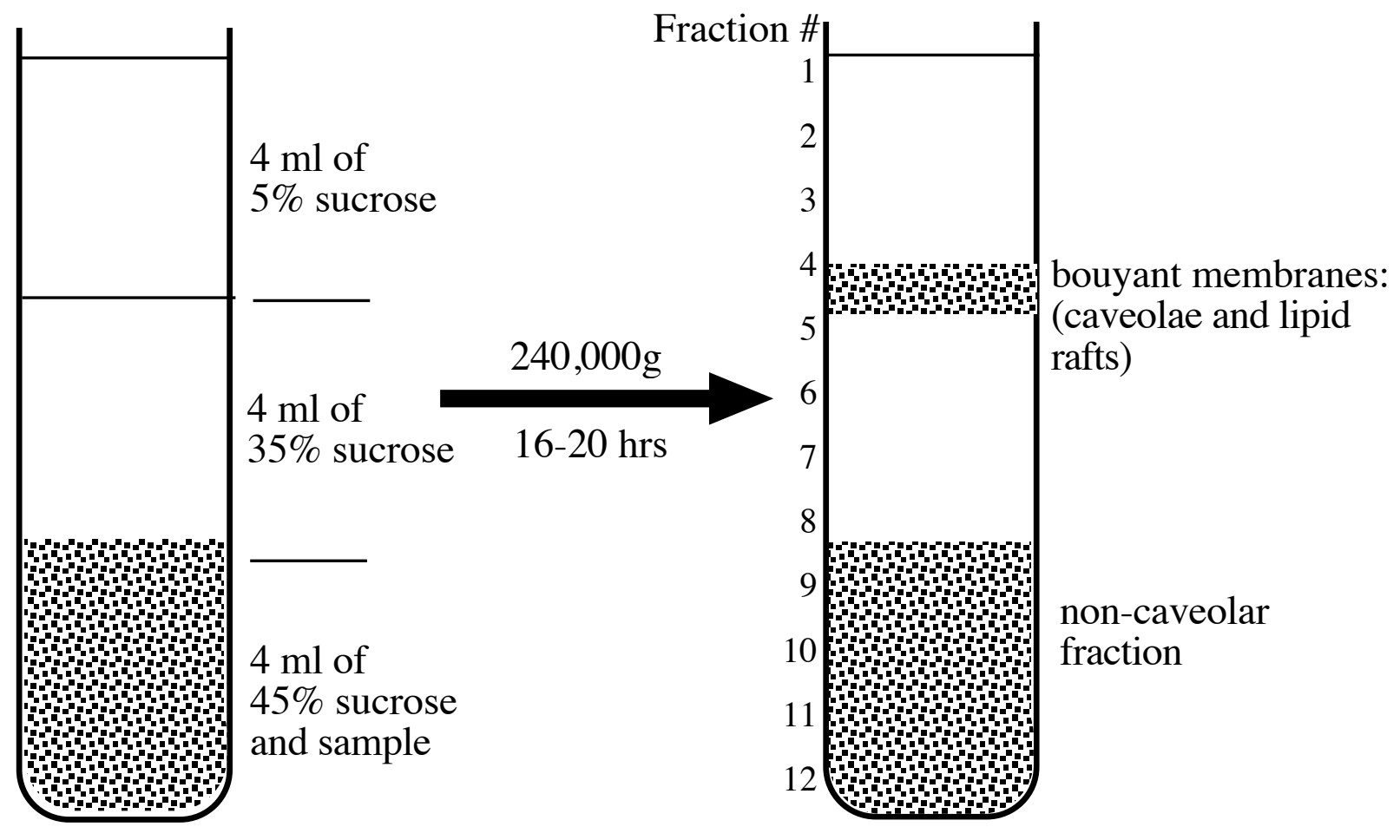

